\title{
The Impact of Cognitive Integration between the Traditional Balanced Scorecard and the Information Technology Balanced Scorecard on the Entrepreneurship Value of the Jordanian Public Shareholding Industrial Companies
}

\author{
Usama Abdul Moneim $^{1}$, Ala Jaber Matarneh ${ }^{1} \&$ Samer Akour $^{2}$ \\ ${ }^{1}$ Jerash University, Jordan \\ ${ }^{2}$ World Islamic Sciences and Education University, Jordan \\ Correspondence: Ala Jaber Matarneh, Jerash University, Jordan. E-mail: alaamatarneh@yahoo.com
}

Received: October 12, 2017

Accepted: December 18, 2017 Online Published: December 20, 2017

doi:10.5539/ijbm.v13n1p153

URL: https://doi.org/10.5539/ijbm.v13n1p153

\begin{abstract}
Due to the increased competition between the various industrial companies at the local and international levels, there became a need to adopt modern and effective methods and tools that enable such companies to acquire and maintain competitive advantages that help them choose, apply and assess the strategies adopted. One of the most important tools is the Balanced scorecard according to the leadership concept and the decisions of the COBIT committee; this tool had a great concern and attention by researchers or businessmen; applying it led to a remarkable success in some companies, which made it move from a mere tool of management to an integrated system of strategic management. The method of measuring the balanced scorecard according to the COBIT committee helps the industrial companies' measure their strategic performance wisely and even goes further in helping formulate the companies' industrial strategies in a pioneer method, translate them into strategic goals, translate these objectives into strategic measurements achieving a follow-up and finally assess the industrial strategy locally and globally. Accordingly, the study aimed at shedding light on the impact of the cognitive integration among the dimensions of the traditional balanced scorecard and the IT balanced scorecard on the Entrepreneurship value in the industrial companies. The study community consisted of all the public shareholding industrial companies listed on Amman Stock Exchange by the end of (2015) amounting to (63) (Annual Report of Amman Stock Exchange, 2016). (56) Companies were randomly selected to form the study sample. One of the most important results of the study is that the effectiveness of measuring the quality of applying the traditional Balanced Scorecard and the IT Balanced Scorecard will create the Entrepreneurship value of the industrial companies, thus contributing to achieving the company's strategic objectives. The study recommended the need that the industrial companies follow up the local and international issues linked with the IT related to applying the balanced scorecard to reach for the institutional leadership with the need that such companies encourage innovation processes, accepting new ideas and motivating employees to provide innovative ideas.
\end{abstract}

Key words: Balance Scorecard, IT Governance, Cobit, Entrepreneurship

\section{Introduction}

The Balanced Scorecard is considered one of the most modern administrative systems working on translating the vision, strategies and mission of the company into strategic objectives, which are shown in multiple dimensions through using financial and non-financial performance metrics, through which the overall position, center and strength of the company can be discovered. There are many names for the Balanced Scorecard; the trend of many companies towards using the Balanced Scorecard stems from their need for being the best, the successive criticisms of the traditional financial and non-financial measurement systems, which are no longer useful in this great, competitive era among the businesses, and the presence of four perspectives on which the Balanced Scorecard focuses on during the measurement process, which are: (the financial axis, the customers' axis, the internal processes axis, and the growth and learning axis), which together form a coherent system able of analyzing both the internal and external environments. However, such balanced scorecard face many criticisms, which led to the creation of a developed scorecard in light of the regulations of the COBIT committee, which is 
intended to show by this study.

\subsection{Study Problem:}

The economic units face many dangers resulting from the changes in the operation environment, the use of new or updated information systems, and the application of new technologies, such as the IT Balanced Scorecard techniques, which requires internal control procedures through a method decreasing such risks and dangers in the Jordanian industrial companies. Therefore, the leadership company has the initiative of adopting new ideas, seeks to discover and increase opportunities, owns the spirit of risk, clear vision, and ability to plan and deal with obscure conditions to add value for or develop its products to achieve profit and growth at the local and international levels, moreover they should exploit the IT potential for shaping new strategies (not only for supporting existing strategies), and identify relation between the costs of IT and final financial performance. Benefits and profits received from systems (Swierk \& Mulawa, 2014). Accordingly, the current study adopts the following main problem:

Is there a statistically significant effect for the cognitive integration between the dimensions of the traditional Balanced Scorecard and the IT Balanced Scorecard on the Entrepreneurship value in the Jordanian public shareholding industrial companies?

\subsection{Research Importance and Contribution}

The attention and realization of the IT systems is necessary for setting the bases of the importance of control on the unit as a whole. The Information Systems Audit and Control Organization (ISIS) has provided a framework for the Control Objectives for Information Technology (COBIT) as a model for IT governance and control, which is simultaneously considered a tool for evaluating IT governance. The COBIT framework in addition to the model of preparing the Balanced Scorecards are beneficial for both the management and auditors through strengthening their viewpoint on the internal control, and providing an opinion and advice on the company's IT controls to reach for the institutional leadership. Moreover, it has been asserted that IT Governance can enhance brand reputation and trust and bring a positive impact on business economic performance, corporate transparency, corporate image, brand value and enhanced reputation as company can increase a company's ability to attract capital and trading partners.

The main interest of this study is that it is conducted to fill a gap and to expand the knowledge in the IT Balanced Scorecard and IT governance literature in Jordan. Most of the literature in the area of IT Balanced Scorecard and IT governance practices has dealt with this subject from the perspective of developed countries, and only relatively little has been written about developing countries, including the country under study, Jordan Thus, the purpose of this research is to explore the extent of IT Balanced Scorecard and IT governance practices by Jordanian Public Shareholding industrial companies and to draw out key issues for future research. Therefore, the main expected contribution of this research is to contribute to the limited studies on IT Balanced Scorecard and IT governance practices on developing countries in general and within the Arabic countries in particular, and to a greater understanding of their accounting problems by examining IT Balanced Scorecard and IT governance practices in Jordan.

\subsection{Study Objectives}

The study aims to achieve the following objectives:

1- Explained the role of COBIT in managing IT Governance.

2- Identifying the role of the COBIT framework and the Balanced Scorecard technique in strengthening governance and internal control procedures during the use of its IT.

3- Highlighting the impact of cognitive integration between the dimensions of the traditional Balanced Scorecard and the Balanced Scorecard of Information Technology on the leadership value of the industrial companies.

\subsection{Study Hypothesis: The study is based on the following main hypothesis:}

There is no statistically significant effect for the cognitive integration between the dimensions of the traditional Balanced Scorecard and the Balanced Scorecard for IT on the leadership value in the industrial companies.

\section{Previous Studies}

\section{(Zhang, 2013), An Exploratory Examination of the Practice of COBIT Framework}

The study aimed to explore the application method of the COBIT framework and its actual use in the IT environment. The study applied an experimental program for the COBIT framework in the IT department as a case study for collecting the initial data where the COBIT tools were analyzed and then compared with the 
theoretical design through identifying and classifying the practical problems; in addition, the COBIT-BSC model was proposed to clarify and simplify the control objectives to the COBIT. The study contributes in having some practical ideas for the practical application of the COBIT framework and helping institutions benefit from the framework features and the frameworks of controlling the other Information Technologies.

\section{Rakthiantam (2013), The Effect of IT Governance on Thai Financial Institution}

The study aimed to examine the effectiveness of the IT governance for organizations through the use of the Balanced Scorecard as a tool of measuring the IT governance. The researchers collected data from 28 financial firms in Thailand. The information gathered focused on applying the IT governance which is expected to improve the corporate organizational performance. Based on the Balanced Scorecard, the study was divided into four parts: companies' contribution, stakeholders, operational excellence, and heading for the future. The study shows that heading for the future affects the operational excellence, which affects the stakeholders, who also affect the companies' contribution. Such relations are considered cause and effect relations. Furthermore, the study noted that the IT governance has a positive impact on the financial companies in Thailand.

\section{(Barbosa,2014), Performance Measurement of Information Technology Governance in Brazilian Financial Institutions}

The study aimed to show that the IT governance is the means by which the organization aligns the IT processes and services with the performance objectives, strategic objectives and results evaluation. The financial sector has benefited greatly from the development of information technology, especially in the field of banks automation. There are few studies and research on describing the IT governance, especially in the financial sector. Therefore, the objective of this study is to measure the IT governance in the financial institutions by the method used in Weill and Ross (2004). The study sample consisted of 60 financial experts from companies in Brazil. The study showed that the average performance was 79.6 and that none of the organizations could achieve the maximum degree of performance, which is 100 despite the fact that many institutions were very close. Such study did not focus only on performance, but also on the importance held by the institutions to each item related to the IT governance and its alignment with the needs and objectives of the organization.

\section{(LudtParmo, 2014), The use of Enterprise Architecture, IT Strategy and IT Governance at StatoilHydro}

This study aims to identify the architecture and building of strategies of the IT and the IT governance through studying the previous literature and developing perceptions on implementing such strategies in StatoilHydro oil and petrol company. It also compares the company's implementation of the IT strategies and the IT governance and examines the company's realization of the IT concepts.

The previous literature, studies and documentations have been used to develop perceptions of IT strategies, architecture and IT management. The study also analyzed and reviewed the documents governing the process of information technology governance, strategies and interviewing people concerned. The study also analyzed the relation of Statoil Hydro to the concepts and strategies of the IT governance and comparing them to the predetermined scenarios.

\section{Theoretical Framework}

\subsection{Balanced Scorecard Definition}

For many decades, measuring and evaluating the performance of companies were limited to the financial results only, which is not enough to ensure that the company achieves its vision and mission leading that many companies head for adopting a clear methodological method for measuring performance through the financial and non-financial results. (Abd Al-Latif and Turkman, 2006). (Kaplan and Norton, 1992) have proposed a reliable method for measuring and evaluating the performance that includes a group of financial and non-financial measures, which is called the Balanced Scorecard (BSC) "(Abd Al-malik, 2006). Abd Al-Latif and Turkman, 2006, 54) stated that the companies' need for a comprehensive database of their performance contains all the necessary measurements to determine the value of the company, whether financial or non-financial, which is one of the most important reasons resulting to the establishment and use of the Balanced Scorecard since it is considered a balanced thinking method, and an operational tool helping the company to assess its financial, operational and strategic performance in order to achieve its strategic objectives. Therefore, there are many definitions stemming from different viewpoints of the accounting thinking leaders ; for example, (Kaplan \& Norton, 2004) defined it as "a system that provides companies with financial, non-financial and strategic objectives giving them the ability to manage the company and assess its future performance; AbdAlmalik, 2006, 58) showed that it is " an integrated framework for measuring the strategic performance consisting of a set of financial and non-financial measurements, which are consistent with the company's objectives and strategy along 
with the objectives and strategies of the sub-units in the company (sections). Such measurements are connected to each other via the cause-and-effect relationship, which improves the long-term financial results rather than depending on only the financial measurements that improve the short-term financial results. (Thomas, 2007) defines it as a" tool of the institutional performance management aiming to follow up the organization activities and evaluate the performance of profitable and non-profitable companies through the balance between the financial and economic perspective, customers' perspective, internal processes, and learning, growth, innovation and Information Technology". However, (Abu Sharkh, 2012) considers it as "a comprehensive administrative system and a tool for translating the objectives to specific balanced measurements by relying on the financial and non-financial measurements, which are distributed to the four dimensions of the scorecard to develop a business plan that translates the company's strategy into operational strategy. On the other hand, (Nadeem, 2013, 129) showed that it is "an administrative system that aims to help the company translate its vision and strategy into a set of connected strategic objectives and measurements through its dimensions going beyond the financial reports in assessing the performance by relying on the balanced scorecard since the financial report is no longer the only means through which companies can assess their activities and draw their future movements."

\subsection{What is the Balanced Scorecard?}

(Samara and Abd Al-Muneim, 2013, 14) showed that the Balanced Scorecard is a measurement system for clarifying, connecting and applying the strategy of the organization. The environment of the information era in both the industrial and service sectors requires companies to have good capabilities to get a competitive advantage and success. The ability to move and exploit the intangible human cognitive assets has occupied a place more important than the investment and management in the tangible physical assets; the intangible assets in companies empower them to do the following:

1. Develop relationships with consumers in a way that maintains the loyalty of the existing consumers and allows access to new sectors of consumers.

2. Creativity in introducing new products and services to target specific sectors of consumers.

3. Produce products or provide "detailed" services in light of the current or expected needs of consumers in a low cost, high quality and short time.

4. Fill the employees' skills and motivate them for continuous improvements in the operational capabilities, quality, response times to the internal needs of consumers (relationships between different departments and centers of the company), and the external consumers (customers).

5. Disseminate and exploit the information technology, databases and systems.

\subsection{The Balanced Scorecard Importance}

The interest in applying the Balanced Scorecard is of great importance, which is as follows:

1. The traditional performance evaluation systems, which did not help evaluate the performance effectively in the information age environment, the failure of the traditional administrative accounting reporting system in providing the necessary information necessary to improve the future performance of the company's management, lack of information on the method of achieving growth in the company, and increasing the growth rates of funders' limitation and the rates of the voluntary compliance led to searching for alternative measurements to evaluate the performance; the balanced scorecard, established by Kaplan and Norton, is one of the best models of the modern era since it enables connecting the long-term strategy of the company with its short-term activities and enables diagnosing and identifying new areas by which the company become distinguished in achieving the objectives of the company and the consumer (Barbosa, et. al, 2014).

2. applying the Balanced Scorecard at companies enables identifying the real costs of processes and services and showing the method of achieving such costs through analyzing the activities related to the required task; all this is done through the use of financial and non-financial measurements depending on the (ABCL / M); this leads to analyzing the activities through the measurements of each activity derived from the operational standards, especially in the era of information and technology and the overlapping of functions among the departments and its resulted mix among the features of functional specialization in order to reach to an integrated system that combines the processing and the requirements of production and the market with the customers' need (Al-Bashtawi, 2004, 15-16).

3. It provides managers with the cause and effect indicators for their companies; identifying the measurements in the Balanced Scorecard is the basis of the company's strategic objectives and the requirements of competition; through the four perspectives of the Balanced Scorecard, the company can control the financial results and the 
development for building the abilities and intangible assets at the same time; furthermore, the company can find a link among the objectives and measurements of performance measures; such scorecard can give the management a comprehensive picture of the nature of the processes of different businesses (Idris and Al-Ghalbi, 2009, 153-154).

4. Chena et al. (2011) added other objectives for using the balanced scorecard as follows; linking all the sector objectives and levels among each other, following-up the performance of activities in the company easily, realizing the company's mission and objectives, identifying the strengths and weaknesses in the company's performance, developing the operational objectives, helping achieve consistency at work among the departments each of which seek to achieve their goals, achieving consistency in the institutional and group individual performance for the departments in the company, preparing and reading reports easily, and identifying and clarifying the employees' duties.

The dimensions of the Balanced Scorecard include the following: the design of the Balanced Scorecard should allow linking the objectives and measurements within the organization, which is done through taking into consideration the following points:

1. The main aspects of the Balanced Scorecard:

A- The Financial aspect: it includes indicators that measure the profitability of the organization.

B- The customer aspect: it identifies customers and market segments, then identifies the performance indicators for this aspect which might include the following: customer service, new customer service, market share of the organization.

C- Internal processes: the executive mangers identify the internal processes required to be created; such processes enable reaching to the objectives presented and satisfying shareholders. The Balanced scorecard is concerned with developing the new processes and the creative activities to serve and satisfy customers.

D- Growth and learning: Meeting the long-term goals and the international competition requires developing performance and skills in a continuous method; such growth and development is evident in individuals, systems, and procedures.

2 - Perspectives possessed by each aspect: For each aspect of the Balanced Scorecard, the organization identifies the following perspectives:
A- Objectives.
B- Measures (indexes).
C- Criteria (targeted results) Target.
D- Initiatives.

By using the balanced scorecard, the organizations show the method of finding and achieving a value for the current and future customers and the method of developing the internal capabilities to improve the future performance, which is done on the critical activities to find and achieve the value as determined by the motivations and achieve the long-term financial and competitive objectives.

Challenges facing applying the Balanced Scorecard: the most evident challenges facing the application of the Balanced Scorecard as seen by (Jordan, E. \& Musson, 2004) are, Firstly: management and employees' Lack of commitment in the process of applying the Balanced Scorecard. Secondly, no commitment in applying the short-term operational plans and annual budgets by the right time, thirdly, the limitations imposed on the information system meaning the inability of measuring the performance fully, and fourthly, differences among the members of the team in drawing the strategic map and choosing the performance measures, and lastly, Permanent resistance by many parties for managing change. Therefore, researchers see the need to search for another method to develop the mechanism of such card in the era of information technology and the era of governance; this results in what is known as COBIT.

\subsection{What is COBIT? What is the Relation between COBIT and the Balanced Scorecard}

IT governance has recently become an important subject for the IT specialists; many companies are now adopting IT governance to ensure the efficiency of its IT systems taking into account reducing the costs of IT and increasing control on the IT investments which led to setting a number of frameworks related to the IT governance such as ITIL, COBIT, ISO 17799 to provide guidance and tools to improve IT governance. The COBIT framework is the most comprehensive since it provides a general view on the whole life cycle of the IT management. The COBIT framework is a globally accepted set of tools that enable IT executives and IT 
professionals to ensure that IT objectives are aligned with the company's goals. Weill and Ross (2004) define IT governance as a tool for determining decision-making rights and a framework of accountability to encourage the desirable behavior in the use of IT management; COBIT framework is a set of internationally accepted tools enabling executives and IT experts to ensure and test that the IT objectives go in line with the company objectives; therefore, (Weill and Ross, 2004) defined the IT governance as a tool for identifying the rights of taking decisions to encourage the desired behavior in using IT. The IT governance aims to confirm investment in information technology, which will generate an added value for the company, reduce risks through controlling the administrative structures, help the company identify a clear range for the responsibility and follow up all processes through the system records. IT managers focus on five key points by implementing a successful model for the IT governance at companies as follows:

1. The harmonization of the IT governance with the company governance and the business objectives where the executive managers should focus on improving transparency in managing the organization and ensuring that the organization goals were realized properly.

2. Focusing the objectives of IT governance on the harmonization strategies (harmonization between the IT and the business strategies and confirming the business priorities), value delivery (maximizing the value of IT investments), risk management (identifying and reducing IT risks in the right time), Resources management (ensuring the availability of the proper IT resources to meet the current and expected business requirements), and performance management (IT control).

3. Enhancing and establishing comprehensive governance in various fields, such as those covering the whole IT series, IT strategy, IT architecture, investment projects and portfolios, software and application lifecycle, infrastructure, data, resources, service lifecycle and emerging technology.

4. Identifying the proper control practices for the IT governance to help achieve the IT governance objectives (governance committees, official meetings, control bodies, documentation controls, approval mechanisms, and examination to ensure compliance with IT governance).

5. Enhancing the continuous follow-up and improvement for the IT governance model to benefit from the IT governance to a great extent which should be used by organizations as one of the continuous priorities (ensuring the continuous improvement in practicing the IT governance in order to adapt to the changing business environment of IT) for ensuring the success of applying and improving the governance model.

\subsection{IT Governance Components}

IT governance consists of the following three different mechanisms:

1. Decision-making structures: They are considered the most evident executive structure determining the decision-making responsibilities. They are a natural method for generating obligations and duties. As for the organizational units responsible for decision making, they might include committees, executive teams, IT and managers.

2. Harmonization processes: they represent the IT management techniques to ensure a broad participation for the management in using the IT; they also include the official processes including the consistency of the daily behavior with the policies of the information technology and the presence of inputs to the decision makers.

3. Information transfer and exchange (communication) method: It means the communication mechanisms aiming to publish decisions on the information and processes technology governance; the communication mechanism might include advertisements, awareness channels that publish the rules and principles of the IT governance and the policies and results of decision-making processes.

Accordingly, we find that Grembergen and Van Bruggen have amended the Balanced Scorecard to make it more compatible with the IT needs; therefore, the IT department works to provide services throughout the company in addition to the internal users and customers; the IT Balanced Scorecard should exceed the operational level and should be integrated by the company to generate a value for its business, which is done through linking between the balanced scorecard of the company and the IT balanced scorecard at different levels through a clear explanation for the cause and effect relation among the measurements of the outputs (result) and the performance motors as in the following form: 


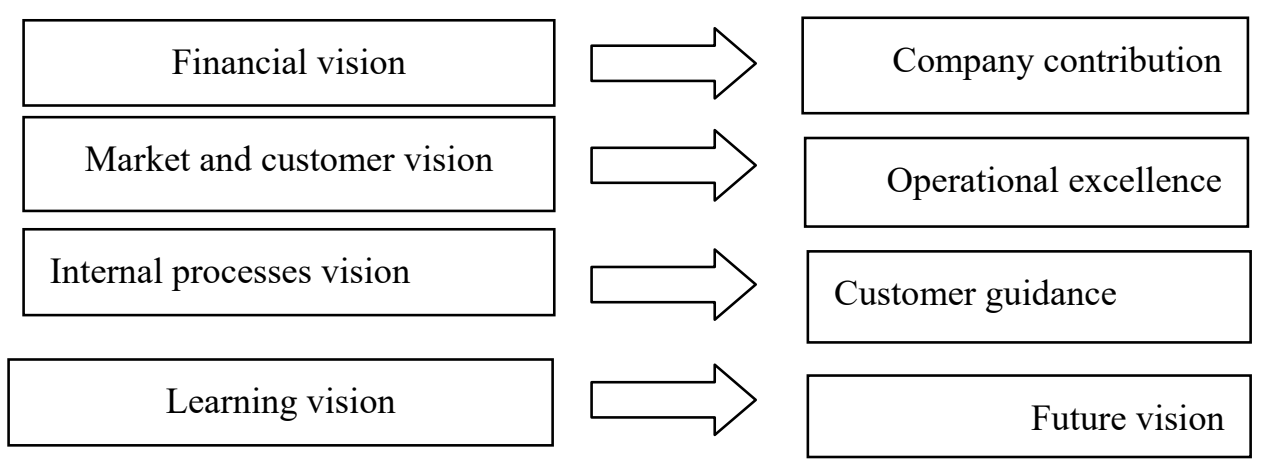

Figure 1. Linking between the balanced scorecard of the company and the IT balanced scorecard

From the Figure 1 and as a part of the company governance, the basic objective of the IT governance is aligning between the IT processes related to the organization with its strategic objectives. Therefore, IT governance is a measurement tool for enhancing the performance of companies by taking advantage of the IT in the business management; from the previous figure, we note that it is consisted of such components that must be translated into measures and procedures to evaluate the current situation. Such assessments should be periodically repeated and consistent with the predefined goals and criteria. The researchers find that such components are correlated with the cause and effect relationship, which allows connection among the two main types of measurements: output (outcome) and performance. In general, developing the IT Balanced Scorecard should start from the company's contribution, which is related to the other components with the cause and effect relation; heading for the future (education and training) might lead to improved information technology and planning (operational excellence), which in turn can improve the level of the stakeholder (stakeholders' trend) and thus affecting the strategic projects of the IT in a positive way. (Company's contribution).

According to the researchers, the proposed standard for linking the IT balanced scorecard with business is through the company's leadership contribution within its business environment; the relationship between the information technology and the company can be expressed more clearly through the balanced scorecard series as shown in the figure below. The Balanced Scorecard developed for IT and the operational Balanced Scorecard for IT are tools for the IT balanced scorecard, which is in turn the balanced scorecard of the company; such sequence of scorecards becomes a coherent set of tools that might be effective in aligning the company's strategies and the information technology and thus helping determine the method of creating a value for the businesses through IT. Figure 2 illustrates this:

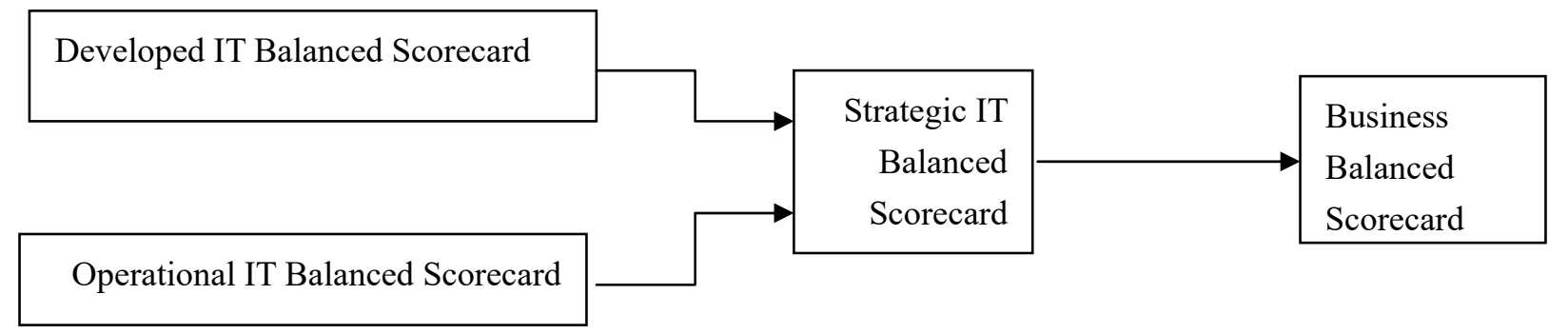

Figure 2. Balanced Scorecards cascade

Accordingly, researchers see that IT plays a pilot role in regards with the regulatory information since the IT components are among the most important assets. Lack of governance of information stored, processed and produced by company's information systems can have a significant negative impact on the company's reputation; damaging this reputation may take a long time and lead to draining energy and money to rebuild it locally and globally. Researchers believe that leadership which is sought by companies reflects a phenomenon related to innovation, creativity, discovery of new opportunities and initiative in adopting it within the company, risk, dealing with mysterious circumstances, and need for achievement, which leads to creating wealth and leadership growth, that is embodied by adding new services or improvements for the product of the company. 


\section{Study Methodology}

The study adopted the analytical descriptive method to measure the effect of the dimensions of the continuous improvement on the success factors in the public shareholding industrial companies.

\subsection{Society and Study Sample}

The study society consisted of all the shareholding industrial companies listed on Amman Stock Exchange by the end of (2015) amounting to (63) (Annual Report of the Amman Stock Exchange, 2016). (56) Companies were randomly selected to form the study sample. Such sample is acceptable according to (Sekaran and Bougie, 2010).

\subsection{Sampling Unit}

Defining the target population considered as the crucial and an essential stage in social research since clearly defined population makes the selection of a representative sample more likely. The study sample or their counterparties are those responsible for financial planning, controlling and decision making (supervising, handling, planning, regulating and implement procedures in Jordanian companies). They are able to take appropriate decisions which are commensurate with the nature, progress and interest of the companies based on their experience.

The sampling unit consisted of the production managers, financial managers, marketing and sales managers, IT managers, human resources managers and general managers. 6 questionnaires were distributed to each company so that 336 questionnaires were distributed while 306 questionnaires were retrieved out of which 18 questionnaires were invalid for analysis; accordingly, the number of retrieved and analyzable questionnaires was 288 by a retrieval ratio of $(85.7 \%)$, which is statistically acceptable.

Due mainly to the high technical and professional nature of the questions to be examined and the data collection mechanizing and also to the cost factor involved in terms of the money and time required. Also, some groups due to their lack of interest, generally, in research subject are given low priority. Other participants are totally discarded based on their prior knowledge, even though it might be known that they have relative technical knowledge and experience of the subject that is being researched otherwise it would be difficult and expensive for these participants to be involved in taking part in the research study.

\subsection{Study Tool}

One of the most convenient and widespread techniques that can be used for both descriptive and explanatory research is the questionnaire. An extensive review of the existing literature regarding research problem was the main source from which the ideas of questionnaire were mainly gained; this includes: (a) the existing literature concerning Balanced Scorecard, IT Balanced Scorecard, Cobit 5 (b) Information Technology in the context of developing countries, (c) specialist book, (f) professionals in the area of study. Thus, For the purpose of gathering the empirical data desired in this study, the decision was therefore made to use questionnaire survey in this research

A questionnaire containing the set of special items in each tool of the dimensions of the cognitive integration between the dimensions of the traditional Balanced Scorecard and the IT Balanced Scorecard was designed to determine the level of applying these dimensions in the surveyed companies in addition to the Entrepreneurship value in the industrial companies.

\subsection{Validity and Reliability of the Questionnaire}

A crucial step in conducting any research is establishing the validity and reliability of the questionnaire. Reliability in questionnaire studies relates to the ability of your tool to produce the same results if you tested it many times over, and whether the questionnaire or survey measures what it intends to measure. Every effort was taken to ensure the validity of the questionnaire through the process of questionnaire design, hypotheses are properly designed, consulted expertise persons in IT and Accounting field to elicit their suggestions, and data analysis. One of the most popular statistical tests for measuring the internal consistency or reliability of a study instrument is Cronbach's Alpha test. The result for the study instrument based on Cronbach's Alpha test was 0.855. The result confirms the relatively high consistency of the study instrument. The Cronbach's alpha coefficient was calculated and the results were as follows: 
Table 1. Internal consistency coefficients for the items of the study tool

\begin{tabular}{lll}
\hline No. & Dimension & Alfa value \\
\hline 1. & Integration between the financial dimension and the company contribution & 0.781 \\
2. & Integration between customer dimension and customer trend & 0.692 \\
3. & Integration between internal processes and operational excellence & 0.707 \\
4. & Integration between the dimension of learning and growth and the future vision & 0.784 \\
$\mathbf{5 .}$ & Cognitive integration between the traditional Balanced Scorecard and the IT Balanced & 0.819 \\
& Scorecard & 0.899 \\
6. & Entrepreneurship value in the industrial companies & $\mathbf{0 . 8 5 5}$ \\
\hline
\end{tabular}

The values of the Cronbach alpha internal consistency coefficient for the items of the study tool ranged from (0.692 - 0.899). In addition, the alpha value for all the items was 0.855 . Therefore, all the values are greater than (0.60), which indicates a consistency between the items of the study tool in addition to the reliability of the study tool as well as the ability of depending on it to conduct a statistical analysis.

\subsection{Resources of Data Collection}

The study adopted two types of resources in data collection: primary and secondary as follows:

First: Primary sources of data: they include the data collected based on the study tool.

Second: Secondary sources of data: they include the references, periodicals, scientific books and journals available in libraries as well as the use of the Internet to reach to foreign scientific journals, which have been used in the previous studies.

\subsection{Statistical Methods Used}

The SPSS was used to process the primary data where the following statistical measurements and tests were used:

1 - Percentages, frequencies, arithmetic means and standard deviations for describing the study variables.

2 - Cronbach Alpha test for confirming the reliability of the study tool.

3 - Tests for the harmonization of the model represented in the multiple correlation test and the Durbin-Watson test to test the self-correlation.

4- Multiple linear regression analysis and the Stepwise regression for testing the effect of all the independent variables.

\section{Results}

\subsection{Descriptive Statistics of the Sample Trends}

This part of the study presents the trends of the members of the sample regarding approving the items of the measurement of the cognitive integration between the traditional Balanced Scorecard and the IT Balanced Scorecard and the Entrepreneurship value in the industrial companies, where the arithmetic means, standard deviations and rank were used. The results were as follows:

First, the cognitive integration between the traditional balanced scorecard and the IT balanced scorecard.

Table 2. The arithmetic means and standard deviations for the items of the cognitive integration between the dimensions of the traditional balanced scorecard and the IT balanced scorecard

\begin{tabular}{|c|c|c|c|c|}
\hline Item & Means & $\begin{array}{l}\text { Standard } \\
\text { Deviation }\end{array}$ & $\begin{array}{l}\text { Relative } \\
\text { Importance }\end{array}$ & Rank \\
\hline \multicolumn{5}{|l|}{$\begin{array}{l}\text { Integration between the financial dimension and the company } \\
\text { contribution }\end{array}$} \\
\hline 1. Alignment between the company strategy and the IT strategy & 3.787 & 0.907 & High & 5 \\
\hline 2. Taking leadership decisions related to IT & 3.766 & 0.840 & High & 6 \\
\hline 3. The cognitive mechanism for the business risks management related to IT & 4.043 & 0.721 & High & 2 \\
\hline 4. Achieving returns from investments supported by IT & 3.809 & 0.680 & High & 4 \\
\hline 5. Transparency in disclosing the costs, benefits and risks of IT & 3.553 & 0.928 & Medium & 7 \\
\hline
\end{tabular}


6. Adopting new fields and programs for developing industrial programs

7. Consistency between the IT and the organizational laws and regulations

General scale

Integration between customers and customers' trends

1. Providing information that increases the company's ability in heading towards customers

2. Speed in responding and dealing with the customers' complaints in a short period of time

3. Strengthening relations with customers through adopting communication techniques of a high quality

4. Appropriate use of business applications and technical information and solutions

5. Providing the best goods by adopting modern information means and techniques

General scale

Integration between the dimension of the internal processes and the operational excellence

1. Analysis of internal processes with a core and effective value on the company

2. Identifying the internal processes contributing in applying the business strategies of the company

3. Consistency of the information technologies used with the internal policies of the company

4. The availability of information for the concerned parties at the company helping in taking decisions

5. Continuous improvement for the IT assets for the company

6. Merging the business applications and techniques with the business procedures of the company

7. Taking interest with the IT and the infrastructure treating it

8. Flexibility of IT and its speed response to the surrounding changes of the environment

General scale

Integration between the dimensions of learning and growth and the future vision

1. The availability of qualified and motivated individuals in the business administrations and the IT

2. Development of employees' knowledge and experience

3. Providing training programs suiting the modern technical developments of 3.574

IT

4. Enhancing the culture of the technical knowledge and linking it with the global improvements

5. Development of IT systems and their organizational procedures

6. Harmonization of the cognitive abilities with the development of industrial programs and IT

General scale

The general scale of the cognitive integration between the traditional balanced scorecard and the IT balanced scorecard

3.766

3.766

$\begin{array}{llll}3.872 & 0.850 & \text { High } & 3 \\ 4.085 & 0.880 & \text { High } & 1 \\ \mathbf{3 . 8 4 5} & \mathbf{0 . 3 6 9} & \text { High } & \\ & & & \\ 3.702 & 0.805 & \text { High } & 3 \\ 3.511 & 0.953 & \text { Medium } & 5 \\ 3.681 & 0.980 & \text { High } & 4 \\ 3.723 & 0.852 & \text { High } & 2 \\ 4.021 & 0.766 & \text { High } & 1 \\ \mathbf{3 . 7 2 8} & \mathbf{0 . 6 5 1} & \text { High } & \end{array}$

4.064

0.734

High

2

0.832

High

8

0.870

High

5

0.834

High

6

0.884

High

7

0.791

High

High

High

1

0.722

0.569

High

0.929

High

1

0.840

High

3

0.744

Medium

6

0.755

High

5

0.713

High

High

4

0.868

High

0.420

High

Table 2 shows the general measurement of the cognitive integration between the traditional Balanced Scorecard and the IT Balanced Scorecard which was high in terms of the relative importance where the arithmetic mean was (3.833) and the standard deviation was (0.416). the cognitive integration (the dimension of the internal processes and the operational excellence) was in the first rank by an arithmetic mean of (4.011) and a high 
relative importance. This indicates the cognitive interest of the industrial companies in terms of the continuous improvement of their industrial work to achieve the institutional leadership; the integration between the (financial dimension and the company contribution) occupied the second place by an arithmetic mean of (3.845) and a high relative importance and the integration of the learning and growth dimension and the future vision) ranked third by an arithmetic mean of (3.748), and a high relative importance. Finally, the integration between the customers' dimension and the customers' trends was in the fourth and last rank by an arithmetic mean of (3.728) and a high relative importance.

We also note from table (2) that the consistency between the IT and the laws and regulations came in the first place, in terms of approving the integration between the financial dimension and the company contribution where the arithmetic mean was (4.085) and a high relative importance; this shows the companies' interest for obtaining modern industrial technologies, while the item (Transparency in disclosing the costs, benefits and risks of IT) came in the last rank by an arithmetic mean of (3.553) and a moderate relative importance.

Table 2 shows that (providing the best goods by adopting modern information means and techniques) was ranked first in terms of approving the integration between the customers' dimension and the customers' trends, where the arithmetic mean was (4.021) by a high relative importance, which indicates the companies' trend to adopt the information technology to meet the needs and desires of customers is high, while the item (Speed in responding and dealing with the customers' complaints in a short period of time) came at the last rank by an arithmetic mean of (3.511) and a moderate relative importance.

The table also shows that (taking interest with the IT and the infrastructure treating it) in terms of approving the integration between the internal processes dimension and the operational excellence had the arithmetic mean of (4.660) by a high relative importance. This indicates that the company maintains its data confidentiality to face the competitive situations of other companies working in the same field; however, the item (identifying the internal processes contributing in applying the business strategies of the company) obtained the last rank by an arithmetic mean of (3.787) and a high relative importance.

It has also been found that (the availability of qualified and motivated individuals in the business administrations and the IT) ranked first in terms of approving the integration between the learning and growth dimension and the future vision where the arithmetic mean was (3.915) by a high relative importance. This indicates the companies' interest in providing individuals with distinctive scientific and practical cognitive trend for reaching to leadership; however, (providing training programs suiting the modern technical developments of IT) ranked last with an arithmetic mean of (3.574) by a moderate relative importance.

\section{Second: the Entrepreneurship value in the industrial companies}

Table 3. The means and standard deviations of the items of the Entrepreneurship value in the industrial companies

\begin{tabular}{|c|c|c|c|c|}
\hline Item & Means & $\begin{array}{l}\text { Standard } \\
\text { Deviation }\end{array}$ & $\begin{array}{l}\text { Relative } \\
\text { Importance }\end{array}$ & Rank \\
\hline \multicolumn{5}{|l|}{ Initiative } \\
\hline 1. Taking attention to the creative abilities of employees step by step & 3.634 & 0.987 & Medium & 5 \\
\hline $\begin{array}{l}\text { 2. The availability of the required financial allocations to develop the } \\
\text { employees' abilities and skills }\end{array}$ & 3.660 & 0.815 & High & 3 \\
\hline $\begin{array}{l}\text { 3. Having a clear image on the opportunities and challenges of the } \\
\text { Jordanian environment }\end{array}$ & 3.745 & 0.675 & High & 1 \\
\hline $\begin{array}{l}\text { 4. Seeking towards acquiring the loyalty of employees who have the } \\
\text { initiative spirit in predicting the future }\end{array}$ & 3.642 & 0.705 & Medium & 4 \\
\hline $\begin{array}{l}\text { 5. Devoting the greatest time of employees to encourage the initiative } \\
\text { spirit and build trust with others }\end{array}$ & 3.511 & 0.547 & Medium & 7 \\
\hline 6. Attracting distinctive skills and competencies & 3.723 & 0.682 & High & 2 \\
\hline 7. Accepting the constructive thoughts and suggestions of employees & 3.596 & 0.681 & Medium & 6 \\
\hline General scale & 3.644 & 0.416 & Medium & \\
\hline \multicolumn{5}{|l|}{ Innovation } \\
\hline $\begin{array}{l}\text { 1. Analysis of the surrounding circumstances to discover new methods to } \\
\text { deal with the problems. }\end{array}$ & 3.638 & 0.673 & Medium & 3 \\
\hline 2. Distinctive and high qualifications and capabilities for the company to & 3.660 & 0.600 & High & 2 \\
\hline
\end{tabular}


deal with the renewal and development cases

3. Continuous excellence through having new methods to achieve the 3.681 customers' satisfaction

4. Suitable allocations to support innovations and support innovators' job $\quad 3.617$ at the company

General scale

0.755

0.677

0.364

0.635

1. Practicing creative methods to create an honest case of excellence and 3.660 competition

2. Encouraging competition and creating constructive conflict among 3.638 creative employees

3. Using brain storming methods to create creative thoughts when facing problems and solving them

4. Embracing, continuously encouraging and supporting creators.

General scale

Table 3 shows that the general score of the Entrepreneurship value in the industrial companies was moderate in terms of the relative importance where the arithmetic mean was (3.658) and the standard deviation was (0.343). Furthermore, (creativity) ranked first with an arithmetic mean of (3.681), and a high relative importance. This indicates the conscious understanding of companies regarding the individuals' possession of innovative thinking, while (innovation) ranked second, with an arithmetic mean of (3.649) by a moderate relative importance and the (initiative) ranked in the third and final rank with an arithmetic mean of (3.644), with a moderate relative importance.

Table (3) also shows that (having a clear image on the opportunities and challenges of the Jordanian environment) ranked first in terms of approving the initiative, where the arithmetic mean was (3.644) by a moderate relative importance; this indicates that companies have a cognitive sense by dealing with the surrounding conditions while (devoting the greatest time of employees to encourage the initiative spirit and build trust with others ) came in the final rank by an arithmetic mean of (3.511) by a moderate relative importance. Table (3) also shows that (continuous excellence through having new methods to achieve the customers' satisfaction) came in the first rank in terms of approving innovation, where the arithmetic mean was (3.649) by a moderate relative importance; this indicates that companies seek to achieve the institutional leadership at the local and global levels; (suitable allocations to support innovations and support innovators' job at the company) came in the final rank by an arithmetic mean of $(3,617)$ and a moderate relative importance.

It was also found that (using brain storming methods to create creative thoughts when facing problems and solving them ) in terms of approving creativity had an arithmetic mean of (3.723) by a high relative importance. This indicates the companies' adoption of the brainstorming method to reach to the industrial leadership ideas; however, (encouraging competition and creating constructive conflict among creative employees) has obtained the last rank by an arithmetic mean of 3.638) and a moderate relative importance.

\subsection{Testing the Study Hypothesis}

This part aims to test the study hypothesis, which states:

There is no statistically significant effect for the cognitive integration between the dimensions of the traditional balanced scorecard and the IT balanced scorecard on the Entrepreneurship value in the industrial companies.

The study hypothesis was subjected to the linear regression analysis where the independent variables were represented by the cognitive integration between the dimensions of the traditional balanced scorecard and the IT balanced scorecard while the dependent variable was represented by the Entrepreneurship value in the industrial companies. The results were as follows: 
Table 4. Shows the multiple linear regression model

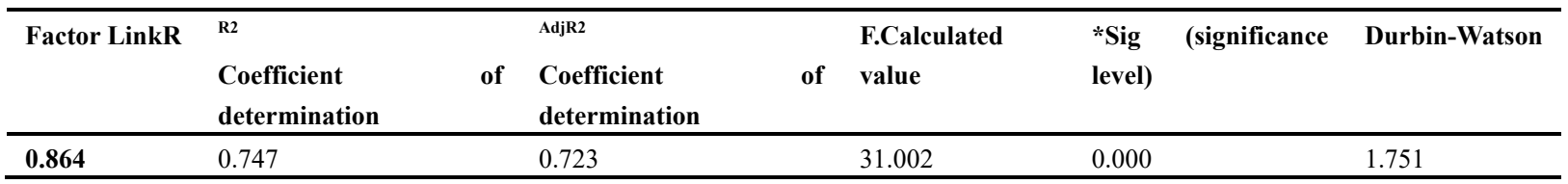

(*) Statistically significant at the level 0.05 .

The table results show that the correlation coefficient $(\mathrm{R}=0.864)$ refers to the relationship between the independent variables and the dependent variable and that the effect of the independent variables (the cognitive integration between the dimensions of the traditional Balanced Scorecard and the IT Balanced Scorecard) on the dependent variable (The Entrepreneurship value of the industrial companies) has a statistical effect where the calculated $\mathrm{F}$ value was (31.002) with a significance level of $(\mathrm{Sig}=0.000)$ which is less than 0.05 ; the coefficient of determination was $(\mathrm{R} 2=0.747)$ which indicates that $(74.7 \%)$ of the variance in the (Entrepreneurship value in the industrial companies) can be explained through the variance in the independent variables.

Table 5. Coefficients of the Multiple Linear Regression model

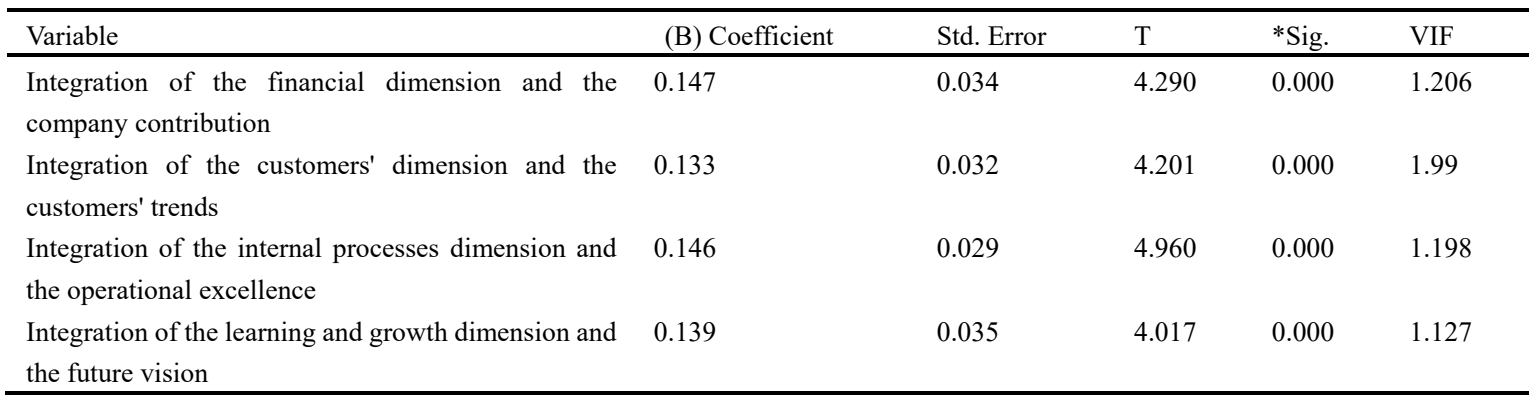

(*) Statistically significant at the level 0.05 .

The table showed that the B value at (the integration of the financial dimension and the company contribution) amounted to (0.147) and the value of $t$ was $(4.290)$ by a significance level of $(\mathrm{Sig}=0.000)$ indicating that the effect of this variable is significant. The $\mathrm{B}$ value at (the integration of the dimension of customers and the customers' directions) amounted to (0.133) and its $\mathrm{T}$ value was $(4.201)$ by a significant level of $(\mathrm{Sig}=0.000)$ indicating that the effect of this variable is significant. The B value at the (Integration of the internal processes dimension and the operational excellence) was (0.146) and t was (4.960) by a significance of $(\mathrm{Sig}=0.000)$ indicating that the effect of this variable is significant. The B value of the (Integration of the learning and growth dimension and the future vision) was (0.139) and the value of t was (4.017) by a significance level of ( $\mathrm{Sig}=$ $0.000)$, which indicates that the effect of this variable is significant.

Based on the above, we reject the main hypothesis and approve the following alternative hypothesis which states:

"There is a statistically significant impact for the cognitive integration between the dimensions of the traditional Balanced Scorecard and the IT Balanced Score Card on the Entrepreneurship value in the industrial companies".

In order to determine the dimension of the cognitive integration between the traditional Balanced Scorecard and the IT Balanced Scorecard which had the most significant impact on the Entrepreneurship value in the industrial companies, the stepwise multiple regression analysis was applied; the results are as follows: 
Table 6. Summary of the model and analysis of variance for testing the main hypothesis

Model summary

\begin{tabular}{llllll}
\hline Model & $\begin{array}{l}\text { Model summary } \\
\text { R. correlation coefficient }\end{array}$ & R2 coefficient of determination & Error of approximation & \multicolumn{2}{l}{ ANOVA variance analysis } \\
& & & & Calculated & \\
\cline { 2 - 6 } & 0.602 & 0.362 & 0.277 & 25.562 & 0.000 \\
2 & 0.749 & 0.561 & 0.232 & 28.130 & 0.000 \\
3 & 0.806 & 0.650 & 0.210 & 26.593 & 0.000 \\
4 & 0.864 & 0.747 & 0.181 & 31.002 & 0.000 \\
\hline
\end{tabular}

(*) Statistically significant at the level 0.05 .

When reviewing the table, we find that the first model resulting from the Stepwise regression analysis indicates that the variable (integration of the financial dimension and the company contribution) explained (36.2\%) of the total variance in (the Entrepreneurship value of the industrial companies); the explanation ratio of the total variance in the (Entrepreneurship value of the industrial companies) amounted to (56.1\%) when adding (the integration of the internal processes dimension and the operational excellence) to (the integration of the financial dimension and the company contribution) in the second model. When adding the variable of (the integration of the customers' dimension and the customers' trends), the explanation ration increased to $(65.0 \%)$ while the explanation ratio reached to $(74.7 \%)$ when adding the variable (the integration of the learning and growth dimension and the future vision) knowing that the different $(\mathrm{F})$ levels in the models fall within a significance level less than $(\mathrm{Sig}=0.000)$, which confirms the significance of the regression.

Table 7. Summary of the Results of the regression coefficients for testing the main hypothesis

\begin{tabular}{lllll}
\hline Model & The leadership in the industrial companies & B & $\begin{array}{l}\text { t. } \\
\text { Calculated value }\end{array}$ & $\begin{array}{l}\text { *Sig. } \\
\text { level }\end{array}$ \\
\hline First & Integration of the financial dimension and the company contribution & 0.243 & 5.056 & 0.000 \\
Second & Integration of the financial dimension and the company contribution & 0.190 & 4.532 & 0.000 \\
& Integration of the internal processes dimension and the operational excellence & 0.161 & 4.465 & 0.000 \\
\multirow{2}{*}{ Third } & Integration of the financial dimension and the company contribution & 0.191 & 5.042 & 0.000 \\
& Integration of the internal processes dimension and the operational excellence & 0.130 & 3.831 & 0.000 \\
& Integration of the customers' dimension and the customers' trends & 0.121 & 3.299 & 0.002 \\
\multirow{2}{*}{ Fourth } & Integration of the financial dimension and the company contribution & 0.147 & 4.290 & 0.000 \\
& Integration of the internal processes dimension and the operational excellence & 0.146 & 4.960 & 0.000 \\
& Integration of the customers' dimension and the customers' trends & 0.133 & 4.201 & 0.000 \\
& Integration of the learning and growth dimension and the future vision & 0.139 & 4.017 & 0.000 \\
\hline
\end{tabular}

Through the results of the table, we find that the B. values in the four models at the different t. levels are at the level of Sig (0.002) or less and for all the variables within the Stepwise regression models which are less than (0.05). This confirms the significance of the regression coefficients, which indicates that the effect of variables in the four models is statistically significant.

\section{Conclusions}

1. The COBIT framework according to the balanced scorecard techniques is considered a global framework that provides directions on the use of the best practices to control the IT.

2. There is an activation of information technology in the Jordanian industrial companies to achieve the strategic objectives in a way suiting the objectives of the traditional Balanced Scorecard.

3. The Entrepreneurship value of the Jordanian industrial companies is still below the expected high level knowing that the industrial sector is one of the most important commercial sectors in Jordan.

4. The effectiveness of measuring the quality of applying both the traditional Balanced Scorecard and the IT Balanced Score Card would create a Entrepreneurship value for the industrial companies, which contributes to achieving the company's strategic objectives.

5. Adopting the IT in the Jordanian industrial companies has become an urgent need for continuous improvement 
of the performance efficiency of companies and directing their business activities to achieve communication in line with the global developments.

6. The general concept of information technologies according to the Balanced Scorecard techniques reflects a group of elements interacting among themselves to conduct certain tasks. Adopting such technologies requires providing a proper environment to comprehend the hardware and software and provide appropriate IT resources, infrastructure and skills.

\section{Recommendations}

1. Both the internal and external auditors may use the COBIT framework according to their balanced scorecard in designing the survey lists or any other means to examine the internal control activities in light of the technical uses.

2. It is necessary to train workers in the Jordanian industrial companies for using the modern uses of information technology to keep up with the latest developments and improve their performance.

3. It is important that the internal audit services contribute to the analysis of it risks periodically in order enhancing the internal control activities, which requires the need to qualify them in a way suiting such techniques.

4. It is important that the accountants and auditors association and the control council contribute in controlling universities to develop the practical training programs for the employees of the Jordanian industrial companies through the computer.

5. The need the industrial companies' follow-up the local and international publications related to the information technology for applying the balanced scorecard to reach to the institutional leadership.

6. The need that the industrial companies encourage innovation processes, accept new ideas and motivate workers to set innovative ideas.

\section{References}

Abd, A. M., \& Ahmed, R. (2006). Balanced measurement as a tool for developing the performance assessment systems in the industrial projects: A theoretical and applied study. The Scientific Journal of Commercial Research and Studies, 81-147.

Abd-Allatif, A. L., \& Turkman, H. (2006). Balanced Scorecard as a tool for measuring performance. Tishreen Journal of Scientific Studies and Research, 28(1), 141-156.

Abu, S., \& Jamal, H. M. (2012). The possibility of evaluating the performance of the Islamic University in Gaza using the Balanced Scorecard (a field study from the point of view of university staff). Unpublished MA thesis, the Islamic University, Gaza, Palestine.

Al-Bashtawi, S. H. (2004). A practical framework for collecting the (operational) financial and non-financial accounting tools of performance in light of competition and the information age: a field study in the Jordanian banks, Damascus University. Journal of Economic and Legal Sciences, 20(1), 387-426.

Barbosa, S. C. B., Rodello, I. A., \& Pádua, S. I. D. D. (2014). Performance Measurement of Information Technology Governance in Brazilian Financial Institutions. JISTEM - Journal of Information Systems and Technology Management, 11(2), 397-414. Retrieved from http://www.jistem.fea.usp.br/index.php/jistem/article/view/10.4301\%252FS1807-17752014000200010

Chena, F., Hsua, T., \& Tzengb, G. (2011). A Balanced Scorecard Approach to Establish a Performance Evaluation and Relationship Model for Hot Spring Hotels Based on a Hybrid MCDM Model Combining DEMATEL and ANP. International Journal of Hospitality Management, 10-11. Retrieved from http://isiarticles.com/bundles/Article/pre/pdf/387.pdf

Grembergen, W. V. (2002). Introduction to the Minitrack: IT Governance and its Mechanisms. Paper presented at the 35th Hawaii International Conference on System Sciences (HICSS), Hawaii. Retrieved from https://www.computer.org/csdl/proceedings/hicss/2003/1874/08/187480242.pdf

Grembergen, W. V., Saull, R., \& Haes, S. D. (2003). Linking the IT Balanced Scorecard to the Business Objectives at a major Canadian Financial group. Journal for Information Technology Cases and $\begin{array}{llll}\text { Applications } & \text { (JITCA), } & \text { R(1). } & \text { Retrieved }\end{array}$ http://www.tandfonline.com/doi/abs/10.1080/15228053.2003.10856015

Idris, W. M. S., \& Al-Ghalebi, T. M. M. (2009). Series of managing the strategic: Performance basics and the 
Balanced Scorecard. Vol.1, Wa'il house of Publishing and distribution, Amman, Jordan. The possibility of evaluating the performance of the Islamic University in Gaza using the Balanced Scorecard (a field study from the point of view).

Jordan, E., \& Musson, D. (2004). Corporate Governance and IT Governance: Exploring the board's perspective, ACIS. Sydney, Australia. $\quad$ Retrieved from http://aisel.aisnet.org/cgi/viewcontent.cgi?article=1151\&context=acis2004

Kaplan, R. S., \& Norton, D.P. (1992). The Balanced Scorecard: Measures that Drive Performance. Harvard Business Review, (January-February), 71-79.

Kaplan, R. S., \& Norton, P. D. (2004). Measuring the Strategic Readiness of Intangible Assets. Harvard Business Review, 52-63.

Lin, F., Chou, S., \& Wang, W. K. (2011). IS practitioners views on core factors of effective IT governance for Taiwan SMEs. International Journal of Technology Management, 54(2), 256-269. Retrieved from http://www.inderscienceonline.com/doi/abs/10.1504/IJTM.2011.039314

Lunardi, G. L., Becker, J. L., Maçada, A. C. G., \& Dolci, P. C. (2013). The impact of adopting IT governance on financial performance. An impirical analysis among Brazilian firms. International Journal of Accounting Information Systems, $\quad$ s15(1), 66-81. $\quad$ Retrieved from https://www.researchgate.net/publication/236851291_The_impact_of_adopting_IT_governance_on_financi al_performance_An_empirical_analysis_among_Brazilian_firms

Nadim, M. S. M. (2013). Assessing the financial performance through the use of the Balanced Scorecard: empirical study in the Royal Jordanian Airlines. Unpublished Master Thesis, Middle East university, Amman, Jordan.

Parmo, C. L. (2009). The use of Enterprise Architecture, IT Strategy and IT Governance at StatoilHydro. Norwegian University of Science and Technology. Retrieved from https://daim.idi.ntnu.no/masteroppgaver/004/4545/masteroppgave.pdf

Rakthiantam, S., Mankongsakul, P., Tiranaprakit, P., Phueknarin, N., \& Chanvarasuth, P. (2013). The Effect of IT Governance on Thai Financial Institution. The 4th International Conference on Engineering, Project, and Production Management. Thailand: Sirindhorn International Institute of Technology (SIIT) and Thammasat University. $\quad$ Retrieved from http://www.ppml.url.tw/EPPM/conferences/2013/download/SESSION4/4-4_The\%20Effect\%20of\%20IT\% 20Governance\%20on\%20Thai\%20Financial\%20Institution.pdf

Samara, M., \& Abd, A. M. O. (2013). The impact of applying the Balanced Scorecard on the Cognitive Capital in the Jordanian public shareholding Industrial Companies: Field Study. Al-Idari Journal, Oman, Sultanate of Oman.

Sekaran, U., \& Bougie, R. (2010). Research Methods. For Business: A Skill- Building Approach (5th ed). New York: John Wiley \& Sons Inc.

Swierk, S, Mulawa. M. (2014). IT BALANCED SCORECARD AS A SIGNIFICANT COMPONENT OF COMPETITIVE AND MODERN COMPANY. Paper presented at Knowledge and learning International Conference $2014 \quad$ Portoroz. $\quad$ Retrieved from http://www.toknowpress.net/ISBN/978-961-6914-09-3/papers/ML14-640.pdf

Thomas, N. G. (2007) Using Balanced Scorecard for Subcontractor Performance Appraisal. Management of Partnerships and Conflict, Kong Hong, China, pp. 7- p15. Retrieved from https://www.fig.net/resources/proceedings/fig_proceedings/fig2007/papers/ts_3g/ts03g_05_ng_2206.pdf

Weill, P., \& Ross, J. (2005). A matrixed approach to designing IT Governance. MIT Sloan Management Review 46(2), 26-34. 2 Retrieved from http://sloanreview.mit.edu/article/a-matrixed-approach-to-designing-it-governance/

Weill, P., \& Ross, J. W. (2004). IT Governance: How Top Performers Manage IT Decision Rights for Superior Results. Watertown: Harvard Business School Press. Retrieved from https://hbr.org/product/it-governance-how-top-performers-manage-it-decisio/an/2535-HBK-ENG

Wilkin, C., \& Chenhall, R. (2010). A review of IT Governance: A taxonomy to inform accounting information system. Journal of Information System, 24(2), 107-146. Retrieved from http://aaapubs.org/doi/10.2308/jis.2010.24.2.107?code=aaan-site 
Zhang, S. (2013). An Exploratory Examination of the Practicability of COBIT framework. Leiden Institute of Advanced Computer Science, The Netherlands. Retrieved from http://liacs.leidenuniv.nl/assets/Masterscripties/ICTiB/Zhang-non-confidential.pdf

\section{Copyrights}

Copyright for this article is retained by the author(s), with first publication rights granted to the journal.

This is an open-access article distributed under the terms and conditions of the Creative Commons Attribution license (http://creativecommons.org/licenses/by/4.0/). 